\title{
Healthy Diets and Regular Exercises to Achieve a Health-Related Quality of Life: A Quasi- experimental Study
}

\begin{abstract}
R.(III). Dioso ${ }^{1 *}$, H. Che Hassan ${ }^{1,2}$, B.F. Abdullah ${ }^{1,2}$ and M.S. Faridah ${ }^{1,2}$
${ }^{1}$ Faculty of Science, Lincoln University College, No. 12-18, Jalan ss6/12, 47301, Petaling Jaya, Selangor

${ }^{2}$ Professor, Lincoln University College, Malaysia, No. 12-18, Jalan ss6/12, 47301, Petaling Jaya, Selangor

This study developed an online health education module on diet and exercise in achieving a healthrelated quality of life. A quantitative quasi-experimental study design was used. A-301 respondents were enrolled for the self-administered questionnaire using the RAND SF-36 of the health-related quality of life as pre- and post-test for both experimental and control group. An online module on diet and exercise was developed as an intervention to achieve a health-related quality of life. The online module on diet and exercise was effective in achieving a significant health-related quality of life ( $\mathrm{p} \leq 0.05)$. Specifically, the domains of the health-related quality of life achieved after 12 months of healthy diets and regular exercises were general health (72.700 \pm 41.1 , po.00915), physical functioning $(82.3200 \pm 51.8$, po.0015), role physical $(92.02 \pm 41.06$, po.001), role emotional (72.706 \pm 21.12 , po.oo), social functioning (96.09 \pm 48.727, po.0012), bodily pain $(99.3 \pm 69.128$,

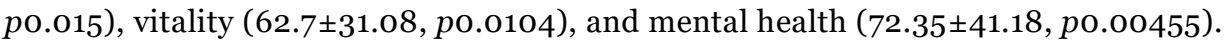

Keywords: health-related quality of life; diet; exercise; health education

\section{INTRODUCTION}

The increasing numbers of people suffering from poor health due to poor eating habits and lack of regular exercises had lost the benefits of enjoying a health-related quality of life (HRQOL). Non-infectious disease such as obesity according to Ismail et al. (2002), is the result of lack of diet control and regular exercises. On the other hand, the coronavirus as an infectious disease may infect people with a weak body (World Health Organisation, 2020) due to lack of exercise and poor eating habits affecting a health-related quality of life.

An online module is more likely the mode of delivering health education for this generation. The generation 5.0 are particular with online gadgets and social networking.

That is why this study developed an online health education module on diet and exercise in achieving a HRQOL. Furthermore, this study specifically investigated the effectiveness of healthy diets and regular exercises in achieving the 8 domains of the HRQOL.

\section{MATERIALS AND METHOD}

The RAND 36-Item Short Form Health Survey was used as a self-administered questionnaire (Patel et al., 2007) transcribed in the online module as a pre- and post-test material to measure the HRQOL. An online module was distributed to the specific enrolled participants that fell on the inclusion and exclusion criteria.

\section{Inclusion Criteria:}

- Adults between the age of 21-55 years old

- English reading Malaysian

- Residing in Klang Valley

\section{Exclusion Criteria:}

- Age less than 21 years old and more than 55 years old

- Non-resident in Klang valley

- Malaysian non English reader

A total of 301 respondents were purposively selected who primarily answered the self-administered questionnaire 
before commencing with the experiment. The control group will be randomly selected at the end of the experiment. The process of sample size selection was determined by using the sample size formula below.

$$
\begin{aligned}
& \mathrm{n} \quad=\frac{\mathrm{X}^{2} \mathrm{NP}(1-\mathrm{P})}{\mathrm{d}^{2}(\mathrm{~N}-1)+\mathrm{X}^{2} \mathrm{P}(1-\mathrm{P})} \\
& \mathrm{n}=\text { Required sample size } \\
& \mathrm{X}=\mathrm{Z} \text { value (e.g. } 1.96 \text { for } 95 \% \text { confidence level) } \\
& \mathrm{N}=\text { Population size } \\
& \mathrm{P}=\text { population proportion (assumed to be } 0.5 \text { (50\%)) } \\
& \mathrm{d}=\text { degree of accuracy (5\%), expressed as a proportion } \\
& \text { (o.o5, it is margin of error). }
\end{aligned}
$$

The module as the research instrument used the website WordPress.com having a backend and a login interface that enabled the study to make changes and/or add more contents. The experiment was divided into 3 phases.

\section{A. Phase 1: Initial Survey}

Every enrolled participants were called to enquire regarding the understanding of the English terminologies found in the pre-test questionnaire. Furthermore, if the enrolled participants do not understand the pre-test questions found on the RAND 36-Item Short Form Health Survey, the researcher called them through WhatsApp, WeChat, Telegram, Instagram, and Facebook messenger to explain further.

Phase 1 also includes the explanation of the purpose of the experiment and the participants were give the online consent before commencing with phase 2 . Informed consent was obtained from each participant. The participants were also given the freedom to withdraw from the experiment at any time.

\section{Ethical approval}

This study was approved by the ethical committee of Lincoln University College for the use of human subjects with a reference number of LUC/1510/PhDHS/0131151019604L. No human tissues were collected.

\section{B. Phase 2: Health Promotion Stage}

This phase is the instructional stage of the online diet and exercise regime for 12 months. Mediterranean, South beach, Ketogenic, and Vegan diets were used as the dietary regimen. Ingredients and the time schedule were indicated in the online module for the participants to follow and they were only to choose one dietary regimen for 12 months. Lean body mass (LBM) calculation (Lee \& Wan Muda, 2019) was necessary to be explained online to be more specific in structuring the amount of food for the participants. For instance, if an enrollee weighs $200 \mathrm{lbs}$, it is multiplied by 0.25 ; the LBM calculation would be: 20olbs minus 5 olbs $=150 \mathrm{olbs}$ (68kgs). In this case, eating around $2 \mathrm{~kg}$ per $\mathrm{kg}$ of LBM is converted to kilocalories/day $\left(68 \mathrm{kgs}^{*} 2 \mathrm{kcal}=1.36 \mathrm{~kg} / \mathrm{kcal}\right.$ per day) is ideal (Johnstone et al., 2005). Body fat percentage should next be measured. It can be taken at home, at the gym, or in a healthcare facility. These are the two most accurate methods (Marieb \& Hoehn, 2016):

Skinfold Calipers: A skinfold calliper works by pinching one area of the respondents' skin that folds easily (like their belly and back), in 3 to 10 different areas of their body to measure their subcutaneous fat. That measurement is then used in a formula to calculate their body fat percentage. If they have never done this before, they must let a physician or coach do it first and teach them how to read the measurements accurately so they can do it at home.

DEXA (Dual-Energy X-Ray Absorptiometry): A DEXA is an $\mathrm{X}$-ray treatment that measures body composition and can detect bone mineral density, lean body mass, and fat mass with great accuracy. However, they can only be done on a health facility for a comprehensive session.

If the participants already know their body fat \%, they can measure their LBM and then pick their protein intake accordingly (Marieb \& Hoehn, 2016). Their LBM is simply the remaining percentage that is not body fat. If for example, one of the respondents weigh 150 pounds $(68 \mathrm{~kg}$ ) and their body fat percentage is $20 \%$, then their LBM is $80 \%$, which in pounds would be:

- Body fat $\%=20 \% * 150 \mathrm{lb}=30 \mathrm{lb}(13 \mathrm{~kg})$

- Lean body mass $=150 \mathrm{lb}-30 \mathrm{lb}=120 \mathrm{lb}(54.4 \mathrm{~kg})$

In order to maintain their muscle mass while losing weight, input 0.60-0.80 grams per lb of LBM (1.3 to 1.7 grams per $\mathrm{kg}$ 
LBM). In this example, the participants would input 72-96 grams of protein $\left(0.60^{*} 120 \mathrm{lb}\right.$ or $\left.0.80^{*} 120 \mathrm{lb}\right)$. To gain muscle mass, the protein ratio should be between 0.8 to 1.2 grams per lb of LBM (1.7 to 2.3 grams per kg LBM). In this example, they would input 96-144 grams (o.80*120 lb or $1.2 * 120 \mathrm{lb})$ and the standard range of 20-50g of net carbs are advised.

Exercises can be low, moderate, and high intensities based on the basal metabolic rate (BMR). The Mifflin-St.Jeor formula (Lim et al., 2018) will be the easiest to use for calculating the BMR. The respondents will lose kilocalories to burn through exercise by these numbers:

- 1.2 BMR: Little to no exercise

- $\quad$ 1.375 BMR: Light exercise 1-3 days per week

- $\quad$ 1.55 BMR: Moderate exercise 3-5 days per week

- $\quad 1.725$ BMR: Hard exercise 6-7 days per week

- 1.9 BMR: High intensity interval training per week

\section{Phase 3: HRQOL Post Assessment Stage}

The 301 respondents again answered using the RAND 36Item Short Form Health Survey found in the online module. Paired t-test was used to compare the pre- to the post-test results. The control group of 301 randomly selected respondents also answered the survey questionnaire in order to compare the results from the experimental group.

\section{RESULT AND DISCUSSION}

Specifically, the domains of the HRQOL achieved after 12 months of healthy diets and regular exercises were general health (72.700 \pm 41.1, po.00915), physical functioning (82.3200 $\pm 51.8, \quad$ po.0015), role physical (92.02 \pm 41.06 , po.001), role emotional (72.706 \pm 21.12 , po.oo), social functioning (96.09 \pm 48.727, po.0012), bodily pain (99.3 \pm 69.128 , po.015), vitality (62.7 \pm 31.08 , po.0104), and mental health $(72.35 \pm 41.18$, po.00455).

\begin{tabular}{|l|c|c|c|c|c|}
\hline \multicolumn{6}{|c|}{ Table 1. Diet and exercise in achieving a HRQOL } \\
\hline \multirow{4}{*}{} & \multicolumn{2}{|c|}{ Paired Differences } & t & df & \multicolumn{1}{c|}{ Sig. } \\
\cline { 2 - 6 } & \multicolumn{2}{|c|}{$95 \%$ C. I. } & & & \\
\cline { 2 - 6 } & Lower & Upper & & & \\
\hline Diet & -74.71374 & -66.40626 & -33.706 & 99 & .000 \\
\hline Exercise & -82.18108 & -74.69892 & -41.603 & 99 & .000 \\
\hline
\end{tabular}

Using the Kruskal-Wallis test, the distribution of pre- and post-test of the HRQOL is the same across the category of the Mediterranean, South beach, Ketogenic, and Vegan diet (sig. o.0o), similarly with low, moderate, and high intensity interval training (HIIT) as regular exercises (sig. 0.0o).

Table 2 shows the diet regimen of the participants distributed in a linear graph. Table 3 also shows the exercise regimen of the participants distributed in a linear graph.

Table 2. Diet regimen

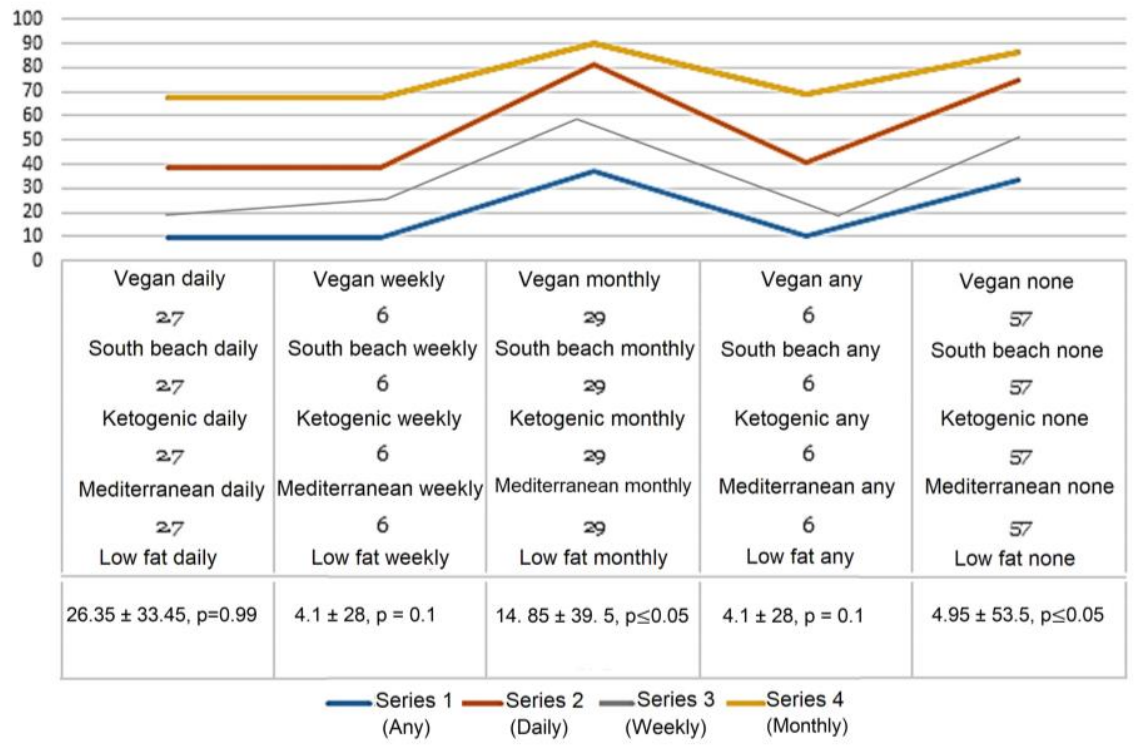


Table 3. Exercise regimen

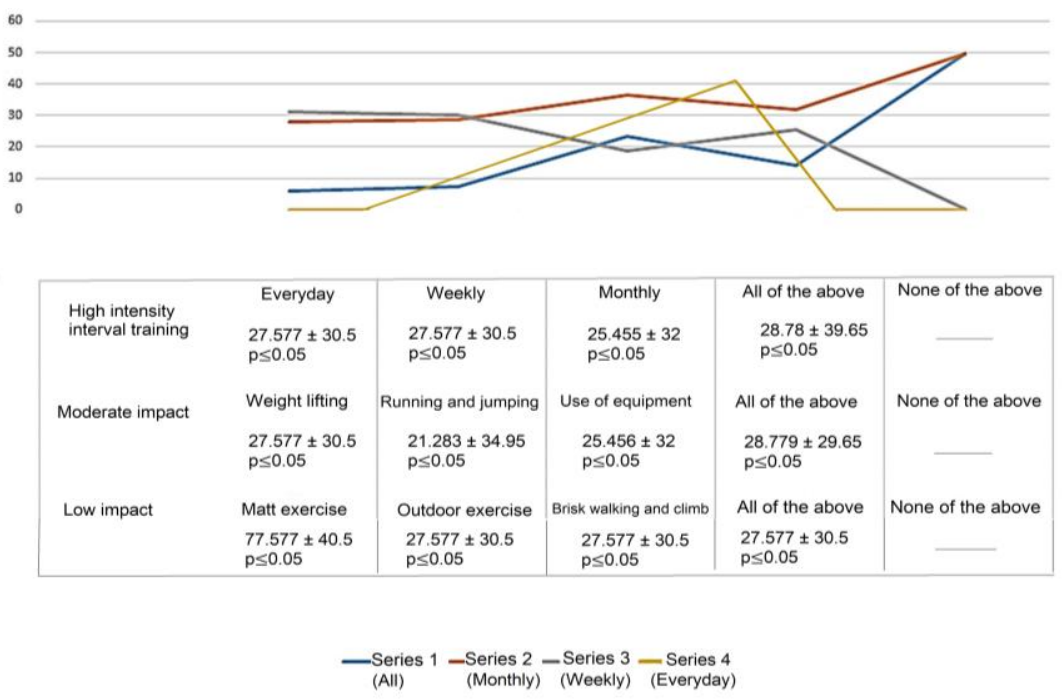

Figure 1 shows the graphical representation of the control and experimental group. This study showed that healthy diets and regular exercises have a significant difference in achieving the HRQOL.

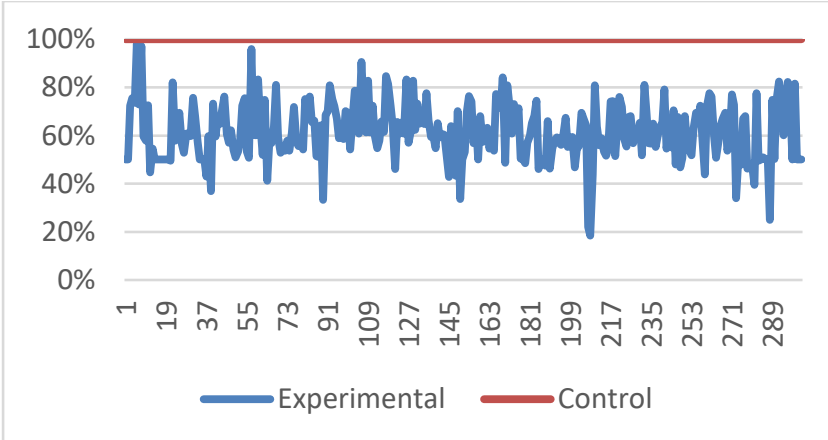

Figure 1. Diet and exercise compared to the control

Using the regression test, the median difference between healthy diets and regular exercises in achieving a HRQOL is significant at $\mathrm{p} \leq 0.05$. This means that diet is related to exercise and vice versa in achieving a HRQOL.

While the distribution of diet (Graph 1) and exercise (Graph 2) using the linear quadratic coefficient of concordance test shows an acceptable significance of $\mathrm{p} \leq 0.05$.

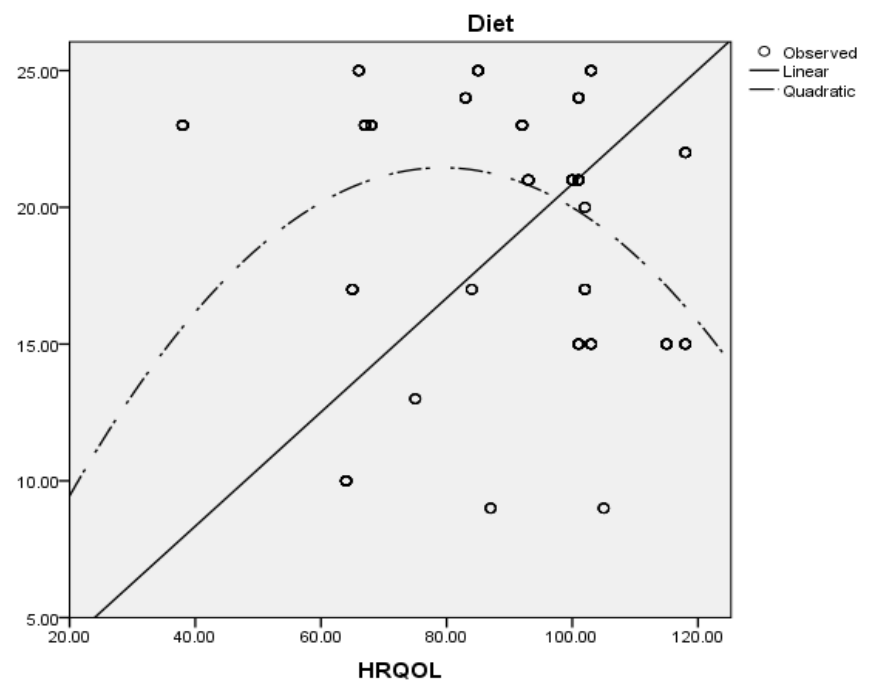

Graph 1. Distribution of diet

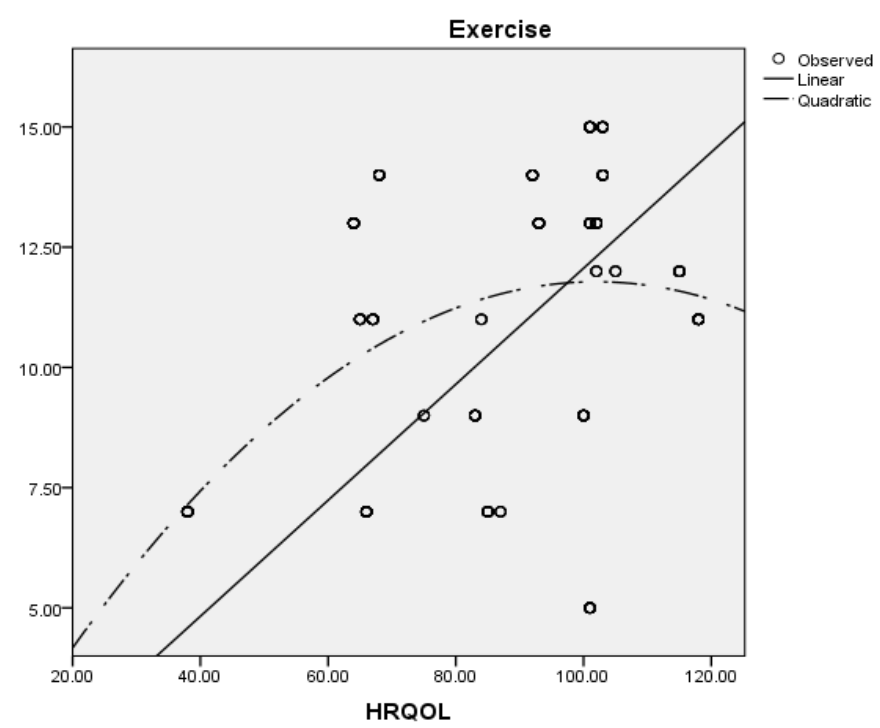

Graph 2. Distribution of exercise 


\section{CONCLUSION}

Healthy diets and regular exercises delivered as health education online can lead to a significant HRQOL. The HRQoL is a broad concept that includes domains related to general health, role physical, physical functioning, mental, emotional, vitality, bodily pain, and social functioning.

\section{ACKNOWLEDGEMENT}

This study would like to thank Edu Punay for the final editing of this written research. It would also like to thank Professor Datin Dr Hafizah Che Hassan for supervising this study. Many thanks also to Lincoln University College staff and administration, especially to Professor Datuk Dr Hjh Bibi Florina Binti Abdullah for all their support.

\section{REFERENCES}

Ismail, MN, Chee, SS, Nawawi, H, Yusoff, K, Lim, TO \& James, WPT 2002, 'Obesity in Malaysia', Obesity Reviews, vol. 3, no. 3, pp. 203-208. doi: 10.1046/j.1467789X.2002.00074.x.

Johnstone, A, Murison, S, Duncan, J, Rance, K \& Speakman, $\mathrm{J}$ 2005, 'Factors influencing variation in basal metabolic rate include fat-free mass, fat mass, age, and circulating thyroxine but not sex, circulating leptin, or triiodothyronine', The American Journal of Clinical Nutrition, vol. 82, no. 5, pp. 941-948. doi: 10.1093/ajcn/82.5.941.

Lee, YY \& Wan Muda, WAM 2019, 'Dietary intakes and obesity of Malaysian adults', Nutrition Research and Practice, vol. 13, no. 2, pp. 159-168. doi: 10.4162/nrp.2019.13.2.159.

Lim, HY \& Wong, SH 2018, 'Effects of isometric, eccentric, or heavy slow resistance exercises on pain and function in individuals with patellar tendinopathy: A systematic review', Physiotherapy Research International, vol. 23, no. 4, pp. e1721. doi: 10.1002/pri.1721. Marieb, EN \& Hoehn, K 2016, Human anatomy \& physiology, 10th edn, in Physiology, Lippincott. doi: 10.1038/nnano.2011.234.

Patel, AA, Donegan, D \& Albert, T 2007, 'The 36-Item Short Form', Journal of the American Academy of Orthopaedic Surgeons, vol. 15, no. 2, pp. 126-134. doi: 10.5435/00124635-200702000-00007.

World Health Organization 2020, Coronavirus, WHO, Geneva, viewed 20 December 2020, $<$ https://www.who.int/healthtopics/coronavirus\#tab=tab_1 $>$. 